Revista de la red interuniversitaria de estudios sobre las literaturas rioplatenses contemporáneas en Francia

$9 \mid 2013$

Homenaje a Ana María Barrenechea

\title{
Ana María Barrenechea, fundadora de objetos críticos
}

Marcela Croce

(apenEdition

Journals

Edición electrónica

URL: http://journals.openedition.org/lirico/1086

DOI: 10.4000/lirico.1086

ISSN: 2262-8339

Editor

Réseau interuniversitaire d'étude des littératures contemporaines du Río de la Plata

\section{Referencia electrónica}

Marcela Croce, «Ana María Barrenechea, fundadora de objetos críticos », Cuadernos LIRICO [En línea], 9 | 2013, Puesto en línea el 01 septiembre 2013, consultado el 20 abril 2019. URL : http:// journals.openedition.org/lirico/1086 ; DOI : 10.4000/lirico.1086

Este documento fue generado automáticamente el 20 abril 2019.

\section{(c) $(1) \odot$}

Cuadernos LIRICO está distribuido bajo una Licencia Creative Commons Atribución-NoComercialSinDerivar 4.0 Internacional. 


\title{
Ana María Barrenechea, fundadora de objetos críticos
}

\author{
Marcela Croce
}

1 Un método original para organizar la crítica literaria en la Argentina, más fructífero que la identificación de corrientes sucesivas (con frecuencia estrictamente emparentadas con ejercicios metropolitanos), es la identificación de objetos privilegiados que cumple cada crítico. Si en la década de 1980 David Viñas fue el inventor de la literatura de frontera, Beatriz Sarlo la consagradora de la vanguardia y Josefina Ludmer volvió a centralizar la gauchesca, Ana María Barrenechea los precedió en el impulso desde los años 50. Fue entonces cuando en el $\mathrm{n}^{\circ} 9$ de Buenos Aires Literaria dio a conocer un texto sobre Macedonio Fernández que lo instaló como figura clave de la literatura argentina mediante la indagación de su "humorismo de la nada". Esa práctica inaugural continuó poco más tarde cuando El Colegio de México publicó La expresión de la irrealidad en la obra de Borges (1957). El escritor probablemente más canónico de Occidente en la segunda mitad del siglo XX fue situado como objeto crítico precisamente mediante ese acto, en un libro ajustado a la metodología estilística pródiga en topoi que se volverían clásicos en la lectura de Borges e impregnado por las concepciones filosóficas de quien orientaba el trabajo tesis doctoral de la autora-, José Ferrater Mora. El reconocimiento de Barrenechea como quien estableció los objetos más proliferantes de la crítica argentina, modificando y actualizando permanentemente su labor, es una exigencia de honestidad intelectual.

2 El magisterio de Barrenechea -fue catedrática de Introducción a la Literatura en la Facultad de Filosofía y Letras de la Universidad de Buenos Aires y también dictó clases en el Instituto Superior del Profesorado, donde se formaron algunas de las figuras que retomaron sus planteos- probablemente no registre el mismo reconocimiento que ella dedica a "mis maestros" Amado Alonso y Pedro Henríquez Ureña al comienzo de La expresión de la irrealidad... ${ }^{1}$ Podría especularse que existe una división de dominios detrás de esta doble dedicatoria, según la cual mientras Alonso aporta el rigor del método, Henríquez Ureña ofrece un modelo para su aplicación americana. La creación de Borges como objeto crítico sumada a la de Macedonio, el Cuaderno de bitácora de Rayuela, los 
"temas hispanoamericanos" que la ocuparon en los artículos que reunió en De Sarmiento a Sarduy, la obstinación en la edición filológica del Epistolario de Sarmiento y Félix Frías (que cumplió para la Facultad de Filosofía y Letras en los 90), la discusión brillante en que desarmó la ligera hipótesis tramada por Tzvetan Todorov en torno a la literatura fantástica y la correlativa obra sobre el género en este continente desarrollada junto con Emma Speratti Piñero, son estaciones de un itinerario latinoamericanista que eludió los énfasis y que contribuyó a extender la "fe en nuestra fonética" que proclamaba Oliverio Girondo en el Manifiesto de Martín Fierro hacia la fe en nuestra literatura y nuestra cultura que voceaba José Martí en sus ensayos programáticos. ${ }^{2}$

La resonancia americana de Henríquez Ureña llevó a Barrenechea a editar los ensayos del dominicano para ese emprendimiento filológico extraordinario que es la Colección Archivos. Más apegada a Alonso, en cambio, parece haberse mantenido María Rosa Lida, poco mayor que Barrenechea y compañera de investigaciones en el Instituto de Filología Hispánica de la UBA hasta su traslado a Estados Unidos, pero cuyas preferencias críticas permanecieron en el ámbito peninsular (con la excepción de un estudio sobre el teatro de Sófocles). La erudición que despliega Lida en su libro sobre La Celestina (Lida de Malkiel 1962) resulta inaudita y deja al lector la impresión de situarse ante un monumento, un ejercicio estricto de la escuela filológica alemana capaz de rastrear las fuentes más heterogéneas y recónditas. Aunque hay momentos en que Barrenechea incurre en ciertas prácticas similares -básicamente en las notas al pie que restituyen fuentes y referencias borgeanas en un arco que abarca las bíblicas, las clásicas, las sajonas (así en EIB 23, 27, 49, 106) -, es indudable que su trabajo preserva la proximidad con el receptor que se sostiene acaso en la voluntad pedagógica de la cual prescinde la labor de Lida. Si existe un punto de neta coincidencia entre ambas críticas es el afán omniexplicativo que lleva el rastreo hasta lo escandaloso : a la summa de Lida es posible oponerle una observación como "ese cielo tan azul que pudo parecerme de púrpura, A, 14, referencia a la adjetivación homérica del vinoso mar" (103).

\section{Génesis y genética}

4 La crítica filológica era la primera escala obligada de Barrenechea, dado que se había formado en esa tradición, en la cual el conocimiento de las lenguas (y ante todo de la lengua como sistema) y el rigor de las demostraciones textuales de todas las intuiciones hasta elevarlas a hipótesis inmediatamente confirmadas son requisitos ineludibles. Precisamente el vocabulario filológico aparece sembrado de palabras como "característica", "rasgo", "dominante" que habilitan el ajuste estilístico de una corriente que toma al lenguaje como modelo y se ocupa de los usos peculiares que identifican a cada escritor. Obsesionada por el concepto de "norma" y alerta ante el avance del "desvío" nociones radicales que perturbaban ya el examen saussureano sobre el sistema lingüístico-, la filología acude siempre al lenguaje como espacio de comprobación de lo temático. Los extensos catálogos en que Barrenechea alista las elecciones léxicas borgeanas referidas a las preocupaciones que atraviesan su obra ofrecen una muestra del "estilo apartadizo" que al tiempo que desarrolla una originalidad creativa se muestra renuente a las modas intelectuales, como certifica la reticencia de Borges a las teorías existencialistas, en especial por la exigencia de elección que conllevan.

5 Tal resistencia, junto con la deliberada ignorancia política o directamente la preferencia por opciones reaccionarias por parte del autor motivó el ataque feroz encarado por 
Adolfo Prieto contra Borges (Prieto 1954), que Barrenechea apenas menciona, favoreciendo con ese desinterés el olvido de un libro que apenas si destaca por su encono virulento. Es cierto, no obstante, que en la confrontación inmediata que le depara con Raimundo Lida y con un discípulo favorito, Enrique Pezzoni -quienes admiten "la hondura de sus preocupaciones humanas bajo el aparente juego" (61) en lugar de la pretendida superficialidad de Prieto-, queda condensado todo juicio sobre semejante tentativa. ${ }^{3}$ Fuera del campo político en que otras críticas aspiran a ubicarlo, Barrenechea no solamente mantiene a Borges en los límites de lo textual sino que postula una superposición del escritor con uno de sus personajes, el intelectual Jaromir Hladík del cuento "El milagro secreto". Así como el condenado a fusilamiento que solicita a Dios la gracia de un año de plazo para terminar una obra que debe completar y corregir mentalmente mientras el tiempo se detiene con los soldados empuñando las armas, también Borges acude a procedimientos que facilitan la memorización como si fuera viable prescindir de la escritura : "Por eso se volcó a la invención de prosas muy breves [... ] o de poemas con medida y rima muy marcadas" (12). Sin embargo, la circunstancia de que Hladík sea una víctima del nazismo reclama un elemento extratextual que permite extender la analogía con el autor y sus especulaciones analíticas sobre la propia práctica.

Pero para llegar a tal concordancia entre escritor y personaje es preciso establecer en qué momento queda diseñada la figura autoral. Barrenechea marca la génesis de la escritura borgeana en 1935, cuando "El acercamiento a Almotásim" y los ensayos de Historia de la eternidad "definen plenamente las características que han dado renombre a sus relatos" (11). Sylvia Molloy coincidirá parcialmente con dicha indicación : entregada a reconstruir la operación de invención y trastorno de fuentes que cumple Borges, se fija en el año 1935 por la aparición de Historia universal de la infamia, el texto donde mejor se trasluce el manejo fraudulento de los materiales a fin de producir una literatura original (Molloy 1977). Los ensayos, en cambio, orientan a Barrenechea en la persecución de temas y estilo. En ellos se despliega "un lenguaje que une lo criollo y lo conversacional con cultismos muy acentuados" (13), una "discordia" que en verdad opera como síntesis simétrica a la que instala el concepto de inmensidad en el Río de la Plata, en la frontera del Brasil y del Uruguay donde Borges encuentra "la esencia de lo criollo" (24) en consonancia con los orientales Enrique Amorim y Pedro Leandro Ipuche. En la proliferación de dualidades, lo criollo y lo universal se expresan en un estilo que es a la vez riguroso y apasionado y cuya mejor definición proveyó el propio autor al instalar El idioma de los argentinos (1928) como un libro "enciclopédico y montonero".

7 La preocupación filiatoria de los textos borgeanos promueve el análisis genético empeñado en rastrear borradores, esbozos, adelantos y otras formas de anticipación del texto definitivo. Todavía en los preliminares de lo que décadas después (y especialmente a partir de las teorizaciones de Gérard Genette) Barrenechea adoptará como método de crítica genética, en este libro se limita a procedimientos más tradicionales. La agrupación del vocabulario referido a un tema -una constante del libro- se define como "parentesco" (exacerbado en el caso de la familia de palabras, incluso cuando su aparición no responda a la virtualidad de la gramática sino a la arbitrariedad autoral : así se explican los derivados de "fantasma" como "afantasmado" y "afantasmar", 105). En estos vínculos de corte genealógico, la rigidez filológica se va atemperando en función de la estilística. Los temas ya no se restringen a los topoi cuyo rastreo más minucioso remite a Ernst Robert Curtius, y de hecho en el desajuste entre las previsiones de la literatura europea y las 
creaciones locales queda confirmada la originalidad borgeana en la expresión de la irrealidad.

8 También al orden de la familiaridad corresponden los contactos -a veces reconocidos en tanto "influencias" y otras veces como "plagios", como ocurre con Shakespeare (89) - que el estilo borgeano establece con los usos propios de otros autores. Si en el orden angloparlante el más frecuentado es Thomas De Quincey $(49,64)$, en el dominio hispánico son Quevedo y Unamuno los más evidentes, con un fugaz paso por Torres Villarroel en los ensayos de la década de 1920. No obstante, no es el acomodo del estilo borgeano al de otros autores sino la plasticidad que exhibe y su capacidad de transformación, la base de su productividad. A veces la variación se ofrece entre dos explicaciones de distinto orden, como la psicológica que en "Historia del guerrero y de la cautiva" equivale a la teológica de "Los teólogos" (76) ; otras veces se desliza de lo estilístico a la construcción del relato, como cuando las categorías retóricas se adoptan en tanto principios narrativos; así, en "El Aleph", "existe una aventura que es en sí una especie de 'oximoron"' (66).

9 La amplitud de los léxicos recogidos confirma la voluntad catalogadora de una crítica que construye inventarios y articula colecciones de palabras previamente a dedicarse a estudiar las repercusiones de ciertos usos sintácticos en la obra borgeana. Y precisamente el concepto de "obra" presupone una definición que, antes que enunciada como punto de partida, se va conformando en el transcurso del libro. Congruente con el método inductivo que aspira a explicar la totalidad -la obra- a partir de las parcialidades que la componen, los textos considerados no se limitan a los que Borges escribió y firmó, sino también a aquellos que seleccionó para la Antología de la literatura fantástica (1940). Como el adjetivo borgeano recurrente cuya raigambre encuentra en Quevedo, el propósito abarcativo que sostiene Barrenechea incurre en lo desaforado y a través de ese vocablo recorre toda la textualidad: "Desaforado es palabra que trae el aire sensacional y desbaratador de Quevedo ; aunque abunda más en su primera época, se prolonga hasta las últimas obras" (20).

En cambio, una palabra que le ha sido insistentemente atribuida a Borges es situada por Barrenechea como una elección lateral. De este modo el tópico estudiado por Beatriz Sarlo y elevado a "ideologema de las orillas", que instala en el título Borges, un escritor en las orillas (original: Borges in the edge, libro que resultó de una serie de conferencias dictadas en la Simón Bolívar Chair de Cambridge), parece haber desoído la advertencia inaugural acerca de la frecuencia de "arrabal (en pocos casos orillas)" (Sarlo 1995 : 22). La distancia entre Sarlo y Barrenechea, sin duda, excede la que podría presumirse entre quien inaugura un objeto y quien busca reinstalar su originalidad una vez que dicho objeto ha sido -retomando una frase admonitoria que consta en la "Biografía de Tadeo Isidoro Cruz"- pasible de incontables "repeticiones, versiones, perversiones". En el hiato entre ambos trabajos se advierten las notorias diferencias de estilo y de propósito. Barrenechea cultiva la modestia de la crítica como esperanza antes que como calculada revelación. En ella no se asiste nunca a la suficiencia con que la crítica argentina de la posdictadura enunció sus pretendidos descubrimientos. "Quédenos la esperanza de no haber destruido torpemente el milagro de su arquitectura" (17), inscribe con una cortesía en la cual late la posibilidad de moderar los excesos en que incurrieron las prácticas estructuralistas, posestructuralistas y deconstructivas en que cayeron algunos de sus discípulos y sobre las cuales ella misma alerta en dos de los apéndices que se adosan a la reedición en 1984 de su libro inicial. 
11 El adelanto de esa labor revisora se vislumbra tanto sobre la cautela crítica verificable en la modalización de ciertas observaciones para sustraerse al estilo asertivo, como en la formalización de algunas conclusiones mediante la elaboración de una fórmula impuesta en términos de tentativa metodológica de clarificación y ordenamiento. En el primer caso abundan los adverbios de duda y los subjuntivos: "La forma de presentar los objetos concentrados en el Aleph está quizás inspirada en la Biblia..." (68) / "Podría interpretarse la frase como un medio indirecto" (72) ; en algún ejemplo la modalización es seguida por el imperativo, de modo de no disolver el discurso crítico en la incertidumbre ("En este pasaje se combinan quizás... Compárese La invención de Morel de A. Bioy Casares”, 85).

Junto con dicha estrategia se expanden momentáneamente ciertas especulaciones que tienden a confirmar la circunstancia de que las elecciones operadas por Borges son las más acertadas; así, "la encarnizada persecución del teólogo rival no habría sido más intensa si se hubiera tratado de antagonistas en el amor y en la posesión de una mujer" (75). No es extraña cierta impregnación de la crítica con su objeto confirmada por la calificación de procedimientos de Borges a partir de adjetivaciones ya establecidas como borgeanas, como ocurre con "vertiginosa" en "la danza vertiginosa de visiones del Aleph" (69).

13 En lo que respecta a la constitución de fórmulas, el recurso se confirma como postulación simplificada de conclusiones. La multiplicidad desplegada en el estudio exhibe sobre el final el carácter comprobatorio, demostrativo y no meramente acumulativo y erudito. Si bien la fórmula será un enunciado concreto en la década de 1970, cuando Barrenechea revisite la obra borgeana, en el libro de 1957 adquiere una enunciación algo rudimentaria, de corte más especulativo que apodíctico: “Si quisiéramos resumir en una fórmula general los múltiples valores [...] nos encontraríamos con la misma comprobación que hemos realizado en otros aspectos..." (111).

\section{Del estilo al género}

La filología estudia la manifestación del estilo según la metodología provista por Saussure : por un lado, mediante la asociación entre el plano del significante y el del significado en cada signo ; por el otro, en el cruce de coordenadas entre lo sincrónico y lo diacrónico en el cual es posible comprobar el aserto borgeano "larga repercusión tienen las palabras". A tal segmentación organizativa se añade la tarea de contabilidad aplicada sobre el léxico estudiado por agregación, de lo que resultan los catálogos ya referidos, tendientes a verificar el modo en que "la abundancia se combina con el movimiento y el desorden, asociando las emociones violentas y los sonidos" (33).

En el aspecto diacrónico Barrenechea evalúa los cambios que un significante registra en las diversas épocas borgeanas y, correlativamente, las modificaciones que sufre desde sus usos en fuentes remotas hasta la reformulación en Borges. Las estrategias que emplea el escritor, el modo en que despliega la combinatoria promueven no solamente usos inesperados o anticonvencionales sino asimismo la conversión de lo folklórico en siniestro. Aquellos elementos que garantizaban la presencia de una combinatoria tranquilizadora son sometidos por Borges a una tergiversación según la cual cierta estructura "que podría haber sido trivial, se ahonda y se hace patética acumulando elementos clásicos que unen el prestigio decorativo de la antigüedad con lo monstruoso" (35). La irrupción de lo inesperado es la mecánica habitual del humor borgeano, siempre 
asistido por una ironía implacable que trasunta el escepticismo autoral. Justamente uno de los puntos en que ese escepticismo se manifiesta -y Barrenechea no deja de subrayarlo- es en el chiste que reemplaza "filósofo" por "filólogo" en torno a Nietzsche (36). En ese chiste se justifica el libro mismo : el filósofo Ferrater Mora guía a la filóloga Barrenechea en un emprendimiento sobre aquel autor que, no conforme con entender a la historia como ficción impregnándola de una irrealidad prolijamente rastreada en la sintaxis y los ajustes a estructuras tradicionales, concibe a la filosofía como una rama de la literatura fantástica.

16 Pese a la profusión de referencias y a las múltiples posibilidades en que se enfrasca en numerosas resoluciones de relatos, "el estilo de Borges no es informe y desorganizado" (39). La acumulación promueve repeticiones, es cierto, pero éstas integran variaciones significativas. Los catálogos léxicos documentan la organización a través de la transcripción minuciosa. De hecho, en el análisis estilístico la enumeración es una estrategia para sistematizar la arbitrariedad y conjurar cualquier amenaza de disgregación. La elección léxica aparece motivada por su idoneidad para la "traducción" de ideas ; así, "el adjetivo irrecuperable [...] traduce la lucha inútil del hombre con las horas y su melancolía desesperanzada" (80). También atañe a preocupaciones de índole metafísica como el inicio del tiempo en el momento de la creación "por el hueco que supone antes de la existencia del mundo" (86), un tema luego transitado con una impronta que se balancea entre la filología y la filosofía por George Steiner (Gramáticas de la creación 2011).

Mediante el manejo léxico, la organización sintáctica y la disposición estructural, Borges produce un enriquecimiento estético de temas filosóficos (87), pero su juego erudito dista de la pasión y es proclive a la pesadilla, sobre todo para un ejercicio filológico, ya que instala a la erudición como ficción antes que como sustento crítico; así, en "Tres versiones de Judas" se asiste a una "visión de pesadilla con el doble juego erudito de autoridades ficticias" (88). El juego como modelo organizativo es la analogía más próxima a la equivalencia que traza Saussure entre la lengua y el ajedrez a la hora de explicar el insondable concepto de "valor" : puede ser el mismo ajedrez que regula las alternativas de varios relatos y especialmente un policial como "La muerte y la brújula" que reclama la simetría de mentes entre criminal y detective (es decir entre jugadores), o bien la organización de la lotería y la disposición de las órdenes secretas de la Compañía en "La lotería en Babilonia".

Pero sería reduccionista limitar la crítica filológica a la acumulación léxica y a la identificación de fuentes. El estilo no es sólo una práctica de vocabulario. En este punto Barrenechea se detiene en la sintaxis y lee en ella la formulación de un proceso intelectual (110). En Borges predomina la sintaxis aclaratoria, con cláusulas intercaladas generalmente parentéticas- que dan cuenta de la génesis textual, "como si presentase un modo de escribir que se deja llevar por lo aproximativo y luego corrige o precisa con espíritu más vigilante" (111). En lugar de una corrección que suprime la primera versión, la preferencia borgeana se inclina por hacer permanecer la formulación original de modo de dar realce al proceso de construcción. Sobre tal procedimiento es posible categorizar los signos : de este modo surge "el paréntesis de desconocimiento" (107), que se combina con el uso tradicional del paréntesis para incluir un dato accesorio o de menor jerarquía que opera "como un llamado de atención al lector, como si se subrayase el texto para destacarlo" (110). 
19 El análisis de un rasgo de estilo como el paréntesis es el disparador del texto de Barrenechea y Speratti Piñero sobre la literatura fantástica en la Argentina. Porque Borges se vale del paréntesis para destacar la inseguridad de una opción, pero mediante la estrategia ya establecida de desjerarquizar para subrayar, en las intercalaciones que permite el signo sobreviene la explicación mágica a la que apuesta el autor. Situada como una posibilidad entre otras, la fantástica impulsa al lector a pronunciarse por ella porque resulta la más coherente con la anulación de la realidad y la arquitectura irreal de los textos que la contienen. La investigación sobre literatura fantástica es la derivación lógica de este libro, que al escoger la expresión de la irrealidad como aspecto central convoca una conclusión no sólo adherida a lo fantástico sino necesariamente parcial y que consecuentemente reclama continuidad.

\section{De la filología a la deconstrucción (pasando por la semiótica)}

Tres apéndices acompañan la reedición de 1984 del libro sobre Borges. El primero es un artículo de 1953 cuya sección final resultó incorporada a uno de los capítulos. Los otros dos fueron publicados en la segunda mitad de los años 70. La distancia entre el primero y los finales es abismal. Sin embargo, hay un aspecto formal que afecta a los tres por igual: los artículos aparecen abarrotados de notas en contraposición a la escansión grácil del libro. Varias de ellas remiten a Henríquez Ureña. Una es la que refiere la reseña que el dominicano le dedicó a Inquisiciones cuando apareció en 1926; otra es la que en "Borges y el idioma de los argentinos" ${ }^{\prime 4}$ comienza emparentando la búsqueda de la expresión local con los Seis ensayos en busca de nuestra expresión de Henríquez Ureña. La preocupación de Borges por la lengua nacional trasunta inquietudes típicas del ensayo esencialista propio de los años 20 y 30 en que escribió sus primeros libros. Anticipando lo que Sarlo establecerá como la vocación borgeana de crearle un mito a Buenos Aires, Barrenechea define los dos tópicos centrales de la época, que pueden sintetizarse en "lo criollo" : "la pampa, ya fijada literariamente por Ascasubi, Del Campo, Hernández, Hudson, Güiraldes, y la ciudad, que espera su Dios" (117).

21 Las disquisiciones acerca del idioma argentino atraviesan una serie en la que Barrenechea integra desde Esteban Echeverría hasta Lucien Abeille, salteando inexplicablemente las Cartas de un porteño en las cuales Juan María Gutiérrez polemizó con el periodista español Juan Martínez Villergas. Atenta a las repercusiones literarias de tales indagaciones, hace constar que Borges descarta la lengua "caricaturesca" de sainetes y tangos y desprecia "el arrabalero, por su misma indigencia, como inepto para las grandes aventuras del espíritu" (119). En este sentido, el ejercicio borgeano de la literatura se inserta en la línea de quienes Viñas llamó "gentlemen-escritores", miembros de la oligarquía argentina del siglo XIX, entre quienes el favoritismo de Borges se orienta hacia Eduardo Wilde.

La estilística opera en este trabajo como axiología que se fija en los usos léxicos cuando acarrean valores. El ejemplo que ofrece Barrenechea es el de "lástimas, con valor parecido, en Lugones" (119). Pero la aplicación del método no es tan estricta como en el libro, de allí que integre una categoría dudosa como la de "gusto" donde era esperable un concepto con cierto rigor para explicar el uso dialogal del "vos" en Borges "coincidiendo con el gusto general" (122). Lo que en el libro forma apartados bajo el título general de "Vocabulario" aquí se extiende en una desmesurada nota al pie con el catálogo léxico de 
Inquisiciones, entre cuyas categorías más convocadas figuran -asistidas por los cuantificadores imprecisos que les asigna la crítica- "pocas voces criollas", "bastantes creadas por él", "muchos latinismos", "más tecnicismos teológicos y filosóficos", "expresiones quevedescas y de otros clásicos", "ciertas formas muy españolas de la lengua oral o de la escrita, y poco usuales en el Río de la Plata, que Borges luego va eliminando" (125-126).

El afán cuantificador del artículo naufraga en la multitud de indefinidos y se dedica a enumerar los manejos de Borges con el léxico: derivación, separación, traslación, etimologías. La conclusión estima que el abandono borgeano de ciertos desvíos de vocabulario responde menos a un acriollamiento que a "una estética de formas más simples, con el convencimiento de que la rareza idiomática perturba al lector y envejece el estilo" (129). Acaso en eso radique la convicción de Barrenechea -enunciada oralmente a modo de consejo práctico ${ }^{5}$ - según la cual la crítica, el género más sometido a la jerga y al tecnicismo, inevitablemente envejece.

24 Como confirmación de semejante aserto sobrevienen los otros dos apéndices, entregados a la actualización crítica mediante la incorporación de nuevas teorías. "Borges y la narración que se autoanaliza" aparece en un homenaje a Raimundo Lida ${ }^{6}, \mathrm{y}$ a modo de dedicatoria tangencial Barrenechea indica su lectura de "Notas a Borges" del crítico : "Me perdonará que en homenaje suyo siga algunos de esos caminos sugeridos por él” (130). El cambio metodológico se advierte en que ya no atiende sólo o principalmente al vocabulario sino que se especializa en los procedimientos. La modernización del modelo filológico y estilístico practicado en los años 50 proviene de la incorporación de conceptos e ideas del formalismo que enseñaba en la cátedra universitaria en la década de 1960, antes de presentar la renuncia cuando el 29 de junio de 1966 el general Juan Carlos Onganía, presidente de facto, envió a reprimir a la comunidad académica en la Facultad de Ciencias Exactas (entonces situada en la Manzana de las Luces porteña). Barrenechea replica en esta adopción de nuevos modelos los cambios generados en el campo intelectual argentino de la época, cuando el impacto del formalismo no hizo más que anunciar la llegada del estructuralismo antes de recalar en la deconstrucción, produciendo un viraje en la crítica local que la liberó de una tradición claustral o impresionista y permitió concebir el análisis de textos como una práctica científica (estructural) o filosófica (deconstruccionista).

Las huellas formalistas se advierten no sólo en el método sino también en ciertos conceptos característicos: los listados léxicos son reemplazados por elementos de construcción textual; las elecciones narrativas de Borges siempre apuntan a la posibilidad más poética ; algunas especulaciones lanzadas en "La busca de Averroes" se perfilan en tanto "embrión de otros tantos relatos posibles [...] son relatos potenciales" (133) que escogen el meollo de lo narrativo, aunque es de extrañar que Barrenechea, tan dispuesta a incorporar las selecciones borgeanas operadas en la Antología de la literatura fantástica de 1940 no coloque al mismo nivel los fragmentos elegidos en Cuentos breves $y$ extraordinarios (1955) en los que consta la clave de un relato.

En el orden del vocabulario crítico aparecen frases inesperadas en 1957: "el arte como artificio" (137) en torno a las versiones barajadas en el cuento "El muerto" ; "la autonomía del texto con respecto a su referente externo" (139); "el hecho estético" (139); "la existencia de un extra-texto con el cual el texto mantiene relaciones ambiguas" (140), que es el modo más simple de traducir los vínculos entre la serie literaria y otras series, como la social, que identifican los formalistas rusos. Sin embargo, las resonancias de Tinianov, 
Eichenbaum y Shklovski no carecen de tensión con otros modelos que Barrenechea no abandona por completo sino que busca sumar a las novedades, como el de Louis Hjelsmlev, explícito en el caso en que "por tratarse de una forma, las sustancias (Hjelmslev) pueden ser intercambiadas sin afectar el diseño" (139). Incluso los ejemplos aparecen ahora como enumeración de diversas manifestaciones de una misma forma (138). En la pugna de modelos, el párrafo de cierre se abstiene de dar a alguno de ellos como triunfador y opta por introducir la vislumbre de un tercero, el de la deconstrucción derrideana, obstinada en la triple mención que reúne en un mismo párrafo "la deconstrucción de pre-conceptos", "deconstrucciones de otro tipo" y "la ambigüedad, las paradojas y las tensiones [...] apuntan, aun a su pesar, a esa deconstrucción" (140).

El último apéndice, "Borges y los símbolos", se detiene en "las metáforas y las fábulas esenciales" (141), lo que otorga al artículo cierto aire antropológico subrayado por el reconocimiento explícito de tal enfoque. Al formular sucesivas correcciones -aunque libres de las parentéticas borgeanas catalogadas-, Barrenechea muestra el cambio de sus ideas originales y el recorrido crítico cumplido, que sólo con un exceso positivista podría llamarse "evolución". La nueva propuesta supera los estratos hjelmslevianos para tratar "diversos niveles en tensión" que constituyen el "artefacto" literario (142-143). El paso de la lengua a la literatura, de Hjelmslev a los formalistas, ya era notorio en el Apéndice II ; ahora el salto se produce hacia un dominio extraliterario como el de la antropología (145), no sin confirmar el cambio de léxico crítico, cuya conceptualización exige la renuncia a ciertas notas impresionistas que todavía se desplegaban en la escritura del libro. “Técnicas", "niveles", "selección”, "desciframiento", "capas de interpretación o lecturas" reemplazan ahora la insistencia clásica en los topoi. De ellos a los tecnicismos se cumple un itinerario simétrico al que lleva de la retórica a los procedimientos constructivos y del estilo a la narración. Y aunque la inmersión en lo antropológico evita al previsible Claude Lévi-Strauss, resulta innegable que el vocabulario empleado en este artículo está en sintonía con la antropología estructural.

28 A su vez, aunque sigue siendo evidente la impronta saussureana, se verifica el paso de Saussure a Peirce, de la semiología a la semiótica, de la "relación interna del significante y del significado" a las categorías peircianas que distinguen los signos en índices, íconos y símbolos. La lectura de los símbolos que elige Barrenechea se abstiene de la recaída en los arquetipos para insistir en lo semiótico, diferenciándose así de la corriente de crítica hermenéutica argentina desarrollada por Graciela Maturo, Graciela Ricci y Edelweiss Serra entregada a una persecución de símbolos de raigambre junguiana, convirtiendo en fetiches a ciertos autores especialmente aptos para tal abordaje.

El cierre del artículo, como la clausura del libro, se inclina por lo formular. En la condensación de la fórmula que tiene la estructura lógico-lingüística de la disyunción, propuesta como equivalente de una conjunción ( $\mathrm{A}$ o no $\mathrm{A}=\mathrm{A}$ y no A), la crítica se ajusta al objeto borgeano proclive al álgebra pero fomenta asimismo una hipótesis arriesgada, como deben serlo todas, y que me atrevo a lanzar para proseguir la postulación inicial del lugar de Barrenechea en la crítica argentina. Si al referirse al mito porteño ella abre el campo para los trabajos de Beatriz Sarlo sobre la vanguardia martinfierrista -con el indeclinable protagonismo de Borges-, en el afán formulista que instaló privilegiadamente el estructuralismo y que se apega a los modelos matemáticos convoca los esfuerzos formulares que plasmará Ludmer en $E l$ género gauchesco. Y concomitantemente: si en la línea filológico-estilística del magisterio de Alonso el discípulo notorio es Pezzoni, en la serie americanista promovida por Henríquez Ureña la 
descendencia de Barrenechea es femenina. El papel creciente que adquieren actualmente las mujeres en la crítica argentina es otro de los impulsos eficaces que derivan del múltiple carácter inaugural de La expresión de la irrealidad en la obra de Borges.

\section{BIBLIOGRAFÍA}

Barrenechea, Ana María. La expresión de la irrealidad en la obra de Borges. Buenos Aires : CEAL, 1984.

Barrenechea, Ana María. "Macedonio Fernández y su humorismo de la nada”. Buenos Aires

Literaria, Año I, n 9, junio 1953 (25-38).

Barrenechea, Ana María. Textos hispanoamericanos. De Sarmiento a Sarduy. Caracas : Monte Ávila, 1978.

Barrenechea, Ana María y Emma Speratti Piñero. La literatura fantástica en la Argentina. México : Imprenta Universitaria, 1957.

Henríquez Ureña, Pedro. Ensayos. Buenos Aires : Sudamericana-Colección Archivos, 2000.

Henríquez Ureña, Pedro. Las corrientes literarias en la América Hispánica. México : FCE, 1966.

Lida de Malkiel, María Rosa. La originalidad artística de La Celestina. Buenos Aires : Eudeba, 1962.

Ludmer, Josefina. El género gauchesco. Un tratado sobre la patria. Buenos Aires : Sudamericana, 1988.

Molloy, Sylvia. Las letras de Borges. Buenos Aires : Sudamericana, 1977.

Prieto, Adolfo. Borges y la nueva generación. Buenos Aires : Letras Universitarias, 1954.

Rosa, Nicolás (ed.). Políticas de la crítica. Historia de la crítica literaria la Argentina. Buenos Aires : Biblos, 1999.

Sarlo, Beatriz. Borges : un escritor en las orillas. Buenos Aires : Ariel, 1995.

Sarlo, Beatriz. Buenos Aires 1920 y 1930. Una modernidad periférica. Buenos Aires : Nueva Visión, 1988.

Saussure, Ferdinand de. Cours de Linguistique Générale. Paris : Payot, 1974.

Steiner, George. Gramáticas de la creación. Buenos Aires : De Bolsillo, 2011.

Thénon, Susana. La morada imposible Tomos 1 y 2. Buenos Aires : Corregidor, 2011 y 2004. Edición a cargo de Ana María Barrenechea y María Negroni.

Viñas, David. Indios, ejército y frontera. México : Siglo XXI, 1982.

Viñas, David. Literatura argentina y realidad política. Buenos Aires : Jorge Álvarez, 1964.

\section{NOTAS}

1. En lo sucesivo, EIB. Aunque el libro original es de 1957, la edición manejada en este artículo es la que publicó el Centro Editor de América Latina en su colección "Bibliotecas Universitarias" en 1984. En la "Advertencia" la autora aclara que ha suprimido un esbozo biográfico de Borges que 
entonces le parecía innecesario y agrega tres apéndices que confirman al escritor como un Aleph de la propia crítica ya que a través de ellos "quedan reflejadas en esta edición mis últimas lecturas de Borges, al que siempre retorno en forma inagotable" (9).

2. Excluyo deliberadamente los trabajos de Barrenechea sobre lingüística, gramática y dialectología dado que mi interés en este artículo es estudiar la crítica literaria.

3. Resulta sintomático que Barrenechea no instale el libro de Prieto como lo que pretendió ser : un pronunciamiento del grupo nucleado en torno a la revista Contorno sobre la literatura borgeana. Se advierte así la renuncia a cualquier polémica que tendiera a instalar el objeto de estudio fuera de lo estrictamente estético.

4. La primera versión consta en el Homenaje a Amado Alonso de la Nueva Revista de Filología Hispánica, año VII, n 3-4, 1953 (551-565), con el título "Borges y el lenguaje".

5. Así la escuché durante el proceso de mi tesis doctoral, que ella dirigió.

6. En: Nueva Revista de Filología Hispánica, XXIV, 2, 1975. Homenaje a Raimundo Lida (515-527).

7. En Revista Iberoamericana, XLIII, 100-101, julio-diciembre 1977 (601-608).

\section{RESÚMENES}

Un método para organizar la crítica literaria en la Argentina es detenerse en la definición de objetos que cumple cada crítico. Ana María Barrenechea (1913-2010) inició la práctica en 1953 al publicar un texto sobre Macedonio Fernández que lo instaló como figura clave de la literatura local. Esa decisión inaugural continuó pocos años después con Borges. El escritor probablemente más canónico de Occidente en la segunda mitad del siglo XX fue situado como objeto crítico en 1957 con La expresión de la irrealidad en la obra de Borges. Luego vendría el Cuaderno de bitácora de Rayuela, seguido por la atención a Ricardo Piglia en la narrativa y a Susana Thénon en la poesía. Sin desdeñar los alcances latinoamericanos de sus intereses literarios, explícitos sobre todo a partir de la década del 70, el reconocimiento de Barrenechea como quien estableció los objetos de estudio más proliferantes de la crítica argentina, modificando y actualizando permanentemente su labor, es una tarea que aún resta cumplir.

Une démarche méthodique pour l'organisation de la critique littéraire en Argentine consiste à observer le choix d'objets qu'effectue chaque critique. Ana María Barrenechea (1913-2010) a commencé cette pratique en 1953 en publiant un texte sur Macedonio Fernández qui l'a installé comme une figure clé de la littérature locale. Cette décision inaugurale s'est vue prolongée quelques années plus tard avec Borges. L'écrivain probablement le plus canonique de l'Occident dans la seconde moitié du XXe siècle a été défini comme un objet critique en 1957 avec La expresión de la irrealidad en la obra de Borges. Puis vint Cuaderno de bitácora de Rayuela, suivi par l'attention dispensée à Ricardo Piglia dans le domaine du récit et à Susana Thénon dans la poésie. Sans négliger la portée latino-américaine de ses intérêts littéraires, explicites en particulier à partir des années 70, la reconnaissance de Barrenechea en tant que critique qui a établi les objets d'étude les plus proliférants de la tradition argentine, modifiant et mettant à jour constamment son propre travail, est une tâche qui reste encore à effectuer. 
A method for organizing literary criticism in Argentina is to notice the definition of objects that fulfills every critic. Ana María Barrenechea (1913-2010) began the practice in 1953 when she published a text on Macedonio Fernández who installed him as a key figure in the local literature. That inaugural decision continued a few years later with Borges. The probably more canonical writer of the Western literature in the second half of the twentieth century was set as a critical object in 1957 with La expresión de la irrealidad en la obra de Borges. After that came Cuaderno de bitácora de Rayuela, followed by the attention to Ricardo Piglia in narrative and Susana Thénon in poetry. Without neglecting the Latin American scopes of her literary interests, explicit especially from the 70s, to acknowledge Barrenechea as the person who established the more proliferating objects of study of the Argentine criticism, constantly changing and updating her work, is a task that still needs to be performed.

ÍNDICE

Mots-clés: critique littéraire, philologie, stylistique, littérature argentine

Keywords: literary criticism, stylistics, Argentine literature

Palabras claves: crítica literaria, filología, estilística, literatura argentina

\section{AUTOR}

\section{MARCELA CROCE}

Universidad de Buenos Aires

mcroce@filo.uba.ar 